\title{
Psychological Evaluations for Immigration; Also for Terrorism Prevention
}

\author{
Reuben Vaisman-Tzachor* \\ Department of Psychology, American College of Forensic Examiners Institute, USA
}

Submission: March 29, 2017; Published: April 18, 2017

*Corresponding author: Reuben Vaisman-Tzachor, Department of Psychology, American College of Forensic Examiners Institute, FAPA, DABPS, DABCHS, Director - Counseling Center of Santa Monica - A Psychological Corporation, 1731 Barry Avenue, \# 112, Los Angeles, California 90025 , USA, Tel: (310) 477-6000; Email: vavnik@hotmail.com

\begin{abstract}
Psychological evaluations of immigration applicants have been widely used for over two decades in the U.S. legal system. The principal purpose of these assessments is to assist immigration authorities in making determinations regarding the immigration status of applicants of various categories. This article proposes that the same evaluations conducted to help adjudicate asylum petitions and inadmissibility hearings are also useful vetting devices for terrorism prevention. The systematic application of the now elective psychological evaluations for immigration courts to all such hearings and procedures could help identify would-be terrorists and help law enforcement prevent future attacks on the U.S.
\end{abstract}

Keywords: Psychological Evaluations; Immigration; Terrorism Prevention

\section{Introduction}

Immigration and terrorism had risen to public attention in recent times and frequently become central topics in political discourse of both domestic and international policy. While largely distinct and different geopolitical processes; one involving the movement of people mostly into the U.S.; the other involving guerilla-type warfare waged against the U.S. among others, often they come to be considered in conjunction with one another. And not without reason. Both immigration and terrorism have become in recent years formidable challenges for law enforcement and for policy makers alike.

Immigration of large numbers of undocumented persons and asylum seekers has commanded increasing attention with most notably the ongoing war in Syria and the ongoing drug war in countries South of the U.S. border. But not exclusively. The considerable number of humans around the globe living under oppressive political regimes; with virtually no protection to members of minority groups of all kinds; combined with even larger numbers of humans living in poverty and hopelessness, have all added to the magnitude of the problem. The pressures upon local populations produced by these conflicts and conditions, with the devastation that they wreak upon the personal lives, safety, economy, and civil life of citizens of these nations intensified the desire to escape and find safe havens in the U.S. and elsewhere [1].
On the other hand, the U.S. and its major geopolitical allies in the western world have been engaged in an ongoing war against terrorism since after September 11, 2001. And although the names of the terrorist organizations, from Al-Qaeda to ISIS have changed over time; as have the stated goals and origins for the armed conflict with the U.S. and its western allies, the presence of terrorist threats has not waned in the least. In fact, the danger of terrorist attacks upon the U.S. in the homeland have all but increased, with the advent of online recruitment of what have come to be dubbed "home-grown-terrorists." This threat has been only magnified with infiltration of would-be terrorists into the U.S., often disguised as refugees and innocent immigrants. The challenge for immigration authorities and for law enforcement agencies to strike a delicate balance between allowing the flow of humans in and out of the country and preventing terrorists from establishing bases of operation within the U.S. has been daunting.

\section{The Modern Nexus of Immigration and Terrorism}

The flow of refugees from war-torn countries into the U.S. is not a new historical phenomenon. In fact, thousands of immigrants from all continents flowed during the last hundred years to America from regions afflicted by civil wars and from nations engulfed in armed conflicts. Ordinarily, the majority of these people were accepted into the fold of American society and 
processed through immigration acts adopted for their purpose, allowing subsequent naturalization [2,3]. Increasingly since the 1990's however, the potential for hundreds and perhaps thousands of terrorists flowing into the U.S. under the guise of either asylum seekers or persons' seeking to reunite with their families already in the U.S. has become an ominous reality.

The national commission on the 9/11 terrorist attacks upon the U.S. [4] identified the infiltration of Nawaf al Hazmi, Khalid al Mihdhar, and other Al-Qaeda operatives in 2000 to California as a prelude to the infamous September 11, 2001 attacks on the U.S. It noted that while Hazmi and Mihdhar were ill-prepared for a mission in the U.S. (Neither had spent any time in the West and neither spoke much, if any English), their devotion to AlQaeda and their ability to obtain valid U.S. visas were crucial qualifications to carry out their ultimate plot [4]. Noteworthy here is the lack of meaningful vetting conducted upon visa applicants before the 2001 attacks; a practice which has not substantially changed thereafter.

In similar fashion, the piloting of the commercial airplanes that would ultimately crash into the New York twin towers was heralded by the entry in the Summer of 2000 through the Newark, New Jersey international airport (with valid U.S. visas, of course) of Marwan al Shehhi and Mohamed Atta (also known as the "Hamburg Cell," after their formation origin). They soon joined other Al-Qaeda counterparts Ziad Jarrah in a flight school in Venice, Florida, and later with Zacarias Moussaoui and Ihab Ali in another flight school in Norman, Oklahoma [4]. The fact that both Atta and al Shehhi were German residents was all that was needed to secure a student visa for entry into the U.S. no questions asked. But, what if their application process also required a psychological evaluation? What could have been learned about them that could have prevented the attacks?

In one study Kephart [5], counted 94 terrorists who came into the U.S. as immigrants between 1990 and 2004, and who eventually conducted terrorist attacks in the homeland. Of the 94 foreign-born terrorists who operated in the United States, her study found that about two-thirds (59) committed immigration fraud prior to or in conjunction with taking part in terrorist activity. Of the 59 terrorists who violated the law, many committed multiple immigration violations - 79 instances in all. In 47 instances, immigration benefits sought or acquired prior to $9 / 11$ enabled the terrorists to stay in the United States after 9/11 and continue their terrorist activities unabated. In at least two instances, terrorists were still able to acquire immigration benefits after $9 / 11$, and enter the U.S. with nary a question.

Temporary visas were a common means of entering; 18 terrorists had student visas and another four had applications approved to study in the United States. At least 17 terrorists used a visitor visa - either tourist (B2) or business (B1). There were 11 instances of passport fraud and 10 instances of visa fraud; in total 34 individuals were charged with making false statements to an immigration official. In at least 13 instances, terrorists overstayed their temporary visas. In 17 instances, terrorists claimed to lack proper travel documents and applied for asylum, often at a port of entry. Fraud was used not only to gain entry into the United States, but also to remain, or "embed," in the country. Seven terrorists were indicted for acquiring or using various forms of fake identification, including driver's licenses, birth certificates, Social Security cards, and immigration arrival records. Once in the United States, 16 of 23 terrorists became legal permanent residents, often by marrying an American. There were at least nine sham marriages. In total, 20 of 21 foreign terrorists became naturalized U.S. citizens [5]. And while the number of terrorists among the millions of other undocumented and documented immigrants is miniscule, their negative effects upon the security of our nation cannot be overstated.

After the December 2010 "Arab Spring" and concurrent emergence of the Islamic State as a player in the Middle East however, the flow of immigrants into the U.S. became an even greater source of alarm for immigration and FBI officials alike. The collapse of many Middle East countries' centralized government (e.g., Lybia, Syria, Yemen), created an even more complex and challenging environment within which immigration authorities, U.S. consulates, and U.S. embassies operate. The task of U.S. officials to validate documents of would-be refugees and ascertain the testimonies given by immigrants applying for visas from such countries became virtually impossible. It also meant that the flow of new immigrants almost certainly included many evil-doers who slipped through the broken system of checks and balances ordinarily designed to catch such persons [6].

In a 2016 report published by staffers of Senators Jeff Sessions (R-Ala.) and Ted Cruz (R-Texas) they counted 580 convictions of terrorists who acted within the U.S. in recent years. Of those convicted of terrorist acts, at least 380 , or over $65 \%$ of these were foreign-born. Further illustrating the growing demand to address the nexus of immigration and terrorism, comes a statement of former FBI director Comey [7]. In a statement before the House Committee on Homeland Security in Washington, D.C. on October 21, 2015, then FBI director James B. Comey estimated that at least 250 Americans traveled to Syria and Iraq to join ISIL (Islamic State of Iraq and the Levant) or ISIS (Islamic State of Iraq and Syria). By his estimates, at least half of them have since returned from the fight and are back in the homeland, preparing to strike [7]. It is therefore reasonable to suggest, that the process by which persons traveling into the U.S. does not adequately screen for the potential risk of terrorism, since so many have managed to enter the U.S.

\section{Types of Psychological Evaluations for Immigration Courts}

There are numerous and diverse circumstances which bring people to immigrate to the U.S., and consequently similar number of potential legal considerations for their adjudication which could be assisted by psychological evaluations. Despite their diversity, the cases processed by immigration authorities 
can be generally subsumed under three distinct categories: (1) Legal Immigrants; (2) Undocumented Immigrants, and (3) Asylum Seekers.

The first category of legal immigrants is ordinarily processed through the embassies, consulates, and other State Department entities in the U.S. and abroad according to customary protocols set forth by immigration law. In some of these instances (usually marriage to a US citizen or other family unification processes) there is also reliance on psychological evaluations in order to provide evidentiary support to immigration applications $[8,9]$. This article proposes that with a few exceptions for persons who because of some obvious limitations (e.g., serious disability, advanced age, etc.) do not represent a risk of terrorism, most immigration applications in this category should be also subject to routine psychological evaluations as a vetting device to enhance terrorism prevention.

The second category of undocumented immigrants, is where more commonly psychological evaluations are being used. Those are typically designed to assist immigration authorities in determination of inadmissibility cases against claims of hardship to qualifying relatives [1,9-11]. Ordinarily, undocumented aliens who are deemed inadmissible for immigration purposes claim on behalf of their relatives (usually U.S.-born citizen children, but not exclusively) hardship if the aliens are to be removed from the country. Often in such cases a psychological evaluation is used to assess the strength and dependability of the relationships between aliens and qualifying relatives, and to determine the potential hardship to befall qualifying relatives if the aliens are to be removed [12]. It is hereby recommended that all cases adjudicated for undocumented aliens to be routinely subjected to psychological evaluations to buttress vetting and terrorism prevention efforts within this group.

The third category involves refugees and asylum seekers where psychological evaluations are often conducted, but usually for applicants who are already on U.S. soil and are seeking asylum from persecution in their country of origin. Such psychological evaluations ordinarily are offered in lieu of other evidence about the alleged persecution the applicants have suffered, or are expected to suffer if returned, when other evidence is typically missing. As can be expected, the majority of refugees and asylum applicants leave their countries of origin in haste under threats to their lives. Therefore, they often lack basic evidentiary materials which could corroborate their claims of persecution in their country of origin. Consequently, the only evidence for what had been perpetrated or could have been perpetrated upon them is commonly found in their psychological make-up and emotional reactions, ordinarily in the form of posttrauma syndromes $[1,13,14]$.

The Process and Structure of Psychological Evaluations for Immigration Courts

Psychological evaluations for immigration purposes are usually initiated by either applicants, or their legal representatives, concurrently, or immediately following the filing of immigration applications with U.S. authorities. Ordinarily, the persons applying would meet over the course of a few sessions for several hours with a psychology expert who would interview applicants, observe and record interactions with applicants, and administer a variety of psychological tests. At the conclusion of the evaluation process, the psychology expert produces a written report, which is then submitted to immigration authorities and becomes evidentiary material for consideration in the ultimate ruling. Occasionally, psychology experts are also called upon to testify in legal proceedings about their evaluations and their findings, in order to assist immigration courts in rendering decisions $[1,10,11,14]$.

In the course of interviews and observations with the psychology expert, the applicants produce a historical account of their lives and current circumstances, which are then compared to results of other objective tests used in the process. The applicants are given a series of objective psychological tests which are designed to generate a valid psychological representation of the persons taking the tests. Obviously, the greater the congruence between the accounts of the applicants and their psychological make-up emerging out of their assessment results, the greater the reliability of their historical accounts, which is relevant for terrorism prevention as well. Additionally, the psychological evaluations typically also seek to map the constellation of interpersonal relations the persons applying for immigration are embedded in, the qualities of those relations, and their importance to the applicants and to their relatives $[10,11]$. This dimension is also crucial in assisting immigration authorities in deciding about the fate of the applicants and is also directly relevant for terrorism prevention.

The outcome of the psychological assessment process is then recorded in a written report by the psychology expert which is then submitted to immigration authorities for their consideration. This final step not only allows (as it now does) for immigration authorities to utilize the psychological assessment results in rendering their judgments, but could also allow, if implemented, yet another type of review by homeland security personnel about the relative risk the immigration applicants evaluated pose for terrorism threats.

\section{Information Gleaned in Psychological Evaluations for Immigration}

The information gathered about immigration applicants when undergoing a psychological evaluation, amounts to fairly accurate and complete psychological representations of the persons involved. That means that the immigration applicants' character structures; their developmental tracks; their emotional dilemmas; their personality strengths, and their typical behavioral tendencies are all flushed out. Additionally, major webs of applicants' interpersonal connections, be it familial or social, are also gathered. Including in this interpersonal map of personal connections are persons who had particular 
influence upon the applicants, which is also particularly relevant to terrorism prevention. This, because many of the individuals who launched terrorist attacks are known to have been inspired or radicalized by terrorism recruiters in their respective communities $[10,11]$.

Because psychological evaluations for immigration courts are governed by Federal Rules of Evidence (FRE), they are responsive to the demands set forth by the 1923 Frye Test of Evidence, and by the 1993 Daubert Standard [15-17]. These demands require that information obtained and presented into evidence is based on scientific principles and discoveries which are widely accepted and well recognized in the respective scientific community (Frye), and that evidence offered to the court is reached with reasonable degree of psychological certainty (which would be above $50 \%$ ) or better than chance (Daubert).

Emanating from federal rules of evidence are specific demands for a particular disposition on the part of the forensic psychology expert that are also consistent with prevailing professional standard of care. That means that selection of instruments and procedures for the evaluation would be those which would extract clinically relevant information; that the psychological tests used are commercially available; that the tests' reliability must be considered; that the tests are relevant to the legal issues; that assessment administration is done in a standard fashion; that tests selected are applicable to the population studied (by norms) and for the purpose used; that preference is given to objective tests, and to those which incorporate response style (also known as validity scales) into their scoring and interpretation scheme [18-20].

\section{The Utility of Psychological Material to Terrorism Prevention Efforts}

In a federally funded research project conducted by the author at the behest of President George W. Bush administration at Sandia National Laboratories in Albuquerque, New Mexico between 2002 and 2004, and subsequent publications $[8,10,11,21]$ the case for use of psychological information in terrorism prevention was made. At the core of the argument is that the motivation for individuals to become terrorists is largely psychological, and that particular psychological make-ups could help predict who is more likely to be a terrorist. Consequently, those persons who are found to fit better the psychological profile of would-be terrorists should receive greater scrutiny, and more thorough assessment by immigration and law enforcement authorities.

While the psychological profile of terrorists is not considered a fixed "structure" or a simply identifiable set of static mental characteristics, the research on this topic identified particular personality tendencies and combinations of circumstances, which could lead to higher likelihood of a person becoming a terrorist. As such, certain psychological aspects were isolated as "markers" or factors, which when existing in combination with other factors and identified in a person, could direct authorities to increase scrutiny of that individual.

Among the most notable factors emerging out of this research are the identifiable narcissistic character organization, coupled with particular insults to the person's grandiose sense of self (also known as ego-injuries) in their personal history, and combined with a palpable desire for notoriety. For a complete discussion of these and other isolated psychological factors, which together form a dynamic psychological profile of likely terrorists, please see prior author publications $[8,10,11,21]$.

In similar vein, but in the opposite direction, there are psychological factors which had been commonly identified in immigrants (particularly undocumented and asylum seekers), but which are not typically motivating factors for persons joining terrorist organizations. Because of the horrific conditions of abuse and destitution many undocumented and asylum seekers leave behind; the immensely perilous and often devastating experiences of migration en-route to the U.S.; coupled with many personal losses sustained and fears about survival, leave most with distinct psychological trauma [1]. Consequently, the common psychological profile of undocumented immigrants and asylum seekers is a combination with varying degrees of post traumatic stress disorder, major depressive disorder, and anxiety disorders.

As can be easily observed by the reader, the psychological profiles of undocumented and asylum seekers and the psychological profiles of would-be terrorists are markedly different and distinct. While the first group of immigrants (undocumented, asylum) presents with largely trauma-related symptoms and a psychological image of victims of terrible circumstances, the second group of (would-be terrorists) immigrants presents with narcissism, grandiosity, desire for notoriety, and signs they sustained insults and blows to their sense of self-worth $[8,10,11,21]$.

In many ways, the psychological evaluation of immigrants for terrorism prevention follows the same conceptual framework of prevalent psychological evaluations for suicide prevention. Current standard of care in psychological practice calls for all clinicians to assess and intervene in situations when patients are suicidal. While the American Psychological Association ethics code and most state laws recognize the imperative to prevent death by suicide, they also recognize that clinicians' abilities to predict future behaviors of individuals is no better than chance $[22,23]$. Therefore, current standards call for an assessment of suicide by all clinicians across the board which will produce a measure of risk (e.g., none, slight, moderate, high, grave, imminent, etc.), and a corresponding intervention plan which is commensurate with the assessed level of risk [23]. Ordinarily, the assessment of suicide risk measures a variety of factors which had been found by research to possess a certain degree of statistically reliable predictive value for ultimate suicide 
behavior [24]. Thus, the greater the number of factors and / or the greater the intensity of the suicide risk factors presented by the individual, the higher the level of risk for suicide assigned to the individual. Correspondingly, the greater the assessed risk of suicide, the more urgent and intrusive the preventive efforts are required to thwart the danger (including arrest and involuntary hospitalization). In any event, the ethical guidelines and standard of care do not call for clinicians to accurately predict future behaviors of individuals - only to adequately assess the risk of suicide and intervene accordingly [22,24].

In similar fashion, the psychological evaluation of immigration applicants for terrorism prevention does not seek to predict who will ultimately become a terrorist and who will not, since this is not possible. It only seeks to assign a level of risk of terrorism, which will direct authorities in further preventive efforts commensurate with the assigned level of risk. Similar to the study of suicide, terrorism has also been studied from a psychological perspective and several reliable predictive factors have been identified over the years, which could become the foundation for assignment of terrorism level of risk [8,10,11,21,25-28]. Along with some demographic characteristics (including ethnic membership, religious affiliation, age, gender, etc.), are some psychological markers (mostly emanating from a narcissistic character organization) which are considered to have higher predictive validity for ultimate terrorist behaviors. When such are identified, immigration authorities would be alerted, and exercise their legal authority, including but not limited to, placing a person on the Terrorism Watch-List; placing a person on a NoFlight List; increased surveillance of immigrants allowed into the country, and all the way to denying entry visa into the U.S., to name only some. Obviously, the level of terrorism risk would be compiled from the quantity and intensity of the predictive factors identified in the psychological evaluation, similar to the suicide evaluation. Likewise, the prevention measures to be applied by authorities will be consistent with the level of assessed risk, so that higher level of risk will beget stronger intervention efforts, and lesser level of risk will receive lesser intervention efforts $[8,10,11,21]$.

\section{Illustrative Examples}

The Case of Omer Ali: Mr. Omer Mohammed Ali was a member of the Issaks tribe and a native of Hargeisa, a town in the northern region of Somalia, which by the mid 1980's became the center of ethnic dispute with the government of dictator Siad Barre [29]. Like many of his tribe's youth, he was fifteen years old when he was recruited to fight for the Somalia National Movement (SNM) against the Barre dictatorship. He received paramilitary training, participated in some of the fighting and later became an informant for SNM while his father was still a minister in the government of Siad Barre. With the intensification of the civil war, Ali's family moved to the capital, Mogadishu, where the fighting soon caught up with them there as well. In 1989, attempting to escape the war, Mr. Omer Ali obtained a student visa (I-20) and moved to Seattle, Washington, to live with tribe members and pursue undergraduate studies. Subsequently, some of his family members managed to escape to Kenya and became refugees there, whereas others less fortunate were either tortured and slaughtered (the men), or tortured and raped (the women).

In 1990, Mr. Omer Ali applied for political asylum, which gave him a U.S. work permit which was then periodically renewed until it was finally denied in the late 1990's. He later moved to Southern California, met and married his wife (who was also a member of the Issaks tribe) in 1997, and sired three children with her. She was a naturalized U.S. citizen who escaped the same town a few years after he did, and for the same exact circumstances. He continued his education and managed to obtain certifications to work as an assistant chiropractor and assistant physical therapist and managed to obtain employment in a large medical facility. During the late 1990's Mr. Ali was involved in a physical altercation during a party at his home, which was reported to police because both he and his counterpart were taken to emergency room for treatment of minor wounds. His political asylum applications were subsequently repeatedly denied, and he was eventually ordered to appear before Judge Latimore of Los Angeles Federal Immigration court in early 2000 's for a deportation hearing.

Alarmed by the police report of interpersonal violence, Judge Latimore in 2003 justly raised the concern that Mr. Ali may represent a danger to U.S. society and moved to deport him back to Somalia. Mr. Omer Ali's attorney prevailed upon the judge and hired the author to conduct a psychological evaluation of Mr. Ali and his family and to offer observations and recommendations to the court for consideration. The psychological evaluation revealed that Mr. Omer Ali was traumatized by the civil war in Somalia and the many personal losses he experienced. He tested as a person who avoids conflict and shies from violence, which made him in the past a poor active participant in the SNM military campaign in Somalia. The psychological study also discovered that he scuffled with his friend over an insult that required him to respond with some degree of measured violence to uphold his family honor, as is customary in the Issaks tribe, but not because he wanted to. The evidence suggested that neither participant in the brawl filed an official complaint against the other, and that in fact, they remained friends thereafter. This, the evaluator argued, was more likely a representation of the poor socialization of $\mathrm{Mr}$. Ali to American norms and values than indication of his violent tendencies, and that Mr. Ali represented a very low risk to U.S. society [30].

Analysis of the Case: The attentive reader would have noted that in 1989, Mr. Ali had no difficulty obtaining a student visa (I-20) to enter the U.S., from a country that was engulfed in a bloody civil war. As Ragavan contemporaneously noted, the U.S. had become in those years a haven for thousands of war criminals who tortured and killed millions of their people in 
Haiti, Somalia, Cambodia, El Salvador, Guatemala, Rwanda, and the former Yugoslavia, to name only some (1999). Immigration authorities in his case had conducted absolutely no assessment of this person nor could they have done so when the government institutions in Somalia had all but collapsed. What could have been done at that time, was a psychological evaluation to identify potential risk factors for terrorism affiliation or motives.

It is important to realize that Mr. Omer Ali's entry into the U.S. with a student visa subsequently also allowed him to change his status to asylum applicant, and to remain in the country for an extended period of years. His affiliations and loyalties notwithstanding, the first time he came to the attention of immigration authorities for special consideration and vetting as a potential risk to U.S. society was five (5) years after he first entered the U.S. (!). During this time, Mr. Ali could have wrecked havoc and destruction in the U.S. in many unimaginable ways, if he was so inclined.

Only when Judge Latimore decided she could not allow a violent man permanent resident status without further investigation did he receive the kind of attention he should have received in the first place. Note also that by the time he came to be considered for immigrant status, Mr. Ali had formed other familial ties (Marriage to a naturalized U.S. citizen and having three U.S. born American citizen children) that would have made his deportation that much more difficult to obtain, if such was sought [30].

Equally important and totally missed by immigration authorities at the time, and allowing his free passage as a student in to the U.S., was Mr. Ali's affiliation to a paramilitary organization (SNM), and his father's affiliation to the dictatorship as a minister in Siad Barre's government. Either loyalties of Mr. Ali; to his father and Barre's government, or to membership in SNM should have ordinarily caused his student visa application to be denied. At the very least, his connections should have raised serious concerns, where a more thorough evaluation should have been conducted to reveal his motives in coming to the U.S., but neither raised a red flag.

In retrospect it was discovered through psychological analysis that Mr. Omer Ali was indeed a true refugee escaping the civil war in Somalia, and not a would-be terrorist on U.S. soil. His psychological profile and emotional presentation was of a person who was traumatized by the war that ravaged his country, and someone who is desperately trying to escape the violence. He exhibited no particular strong affiliation loyalties to either party in the conflict, and exhibited none of the characteristic psychological markers found in most terrorists (namely, narcissistic character traits) $[8,10,11,21]$. For a more thorough discussion of the psychological evaluation for asylum applications and its products, see author's 2014 article.

The Case of Syed Rizwan Farook and Tashfeen Malik: Syed Farook became friends with the co-conspirator and collaborator of the San Bernardino terror attack, Enrique Marquez Jr. as a teenager. They both grew up in a suburban tract in Riverside, California, where they began attending a local mosque, discussing Islamic radicalism and amassing weapons and explosives. Four years before the San Bernardino massacre, they hatched terrifying schemes, involving launching pipe bombs into the cafeteria of Riverside City College, shooting people as they fled, and opening fire on drivers on the 91 Freeway during rush hour. Their plot however never came to fruition as in 2012, three other conspirators were arrested in the same region (Inland Empire, California) on suspicion of plotting to kill Americans [31].

Seeking less illustrious venues thereafter, Marquez then married in 2014 Mariya Chernykh, whose sister was married to Farook's older brother. The sisters are from Russia and came on J-1 visas - commonly used for educational and cultural programs. Marquez later admitted to investigators that he was paid to marry her so she can obtain legal status, as did Farook's older brother - in an of itself, a Federal offense carrying 10-15 years in prison. Before the attack in San Bernardino he nonetheless purchased for Farook and his wife Malik two assault rifles that were subsequently used in the massacre.

Sometime in 2012, Mr. Syed Farook met Tashfeen Malik, a Pakistani woman who was raised in Saudi Arabia, and who hailed from a family with reputed ties to Islamic militants in Punjab. The couple met first online through an Islamic matrimonial website, and he subsequently traveled to Saudi Arabia in 2013 to meet her in person. They then obtained a K-1 "fiancee" visa for Malik to enter the country with Farook. In the process, she underwent "extensive counter-terrorism screening" by U.S. immigration authorities which included checks of fingerprints and facial recognition software, and questioned about her intentions to "engage in terrorist activities while in the U.S." [31]. The two married in 2014 in Islam's holy city of Mecca in Saudi Arabia, and returned to the U.S. where they resumed their preparations for the attack. They ultimately launched their terrorist act in December 2015 in Farook's office holiday party in San Bernardino killing 14 and wounding 22 before they were also killed in a police shootout later that afternoon.

Analysis of the Case: There appear to have been a few opportunities for authorities to be alerted to the potential risk that Mr. Syed Farook, his friend Enrique Marquez Jr., and Farook's wife, Ms. Tashfeen Malik represented. First, the marriage of Marquez to Mariya Chernikh and her sister's marriage to Farook's older borther could have alerted immigration authorities to the fraudulent nature of the relationships. While in and of themselves not terrorism-related offenses, they could have trained a spot-light on these individuals and their other, more nefarious activities, and possibly deter them from executing their plot. A routine psychological evaluation for immigration of the two married couples (Farook and Chernikh and Marquez and Chernykh) would have revealed fairly quickly that the couples 
were not romantically involved and fraudulently conceived. If nothing else, it would have put Mr. Farook's older brother and Mr. Marquez Jr. out of the picture with sentences of 10 to 15 years in federal prison each, unable to assist in any future terrorism attacks. While not entirely stopping Mr. Syed Farook from pursuing his Jihad, it could have possibly deterred him from continuing to plot in the absence of his friend and brother, and with greater authority scrutiny upon him.

The other point in time when immigration authorities failed to detect, and could have detected a would-be terrorist was in the processing of the K-1 "fiancee" visa for Ms. Tashfeen Malik. First, it goes without saying that asking a person about their "intentions to engage in terrorist activities while in the U.S." is a naive and ridiculous procedure to vet a person. It is only slightly ahead of an almost equally pathetic and absurd second check of fingerprints and facial recognition software. None of those could nor did identify what was in this woman's mind and heart - namely, that she was going to massacre as many Americans as she could, and that she was going to lie about it all the way to the bloody end. A psychological evaluation of this woman and a psychological evaluation of this matrimony would have revealed essential clues about the personality elements which could portend ultimate terrorist behavior. A thorough review of her developmental history and psychological testing of her character alone would have revealed her narcissistic tendencies and her vulnerability to terrorism recruitment $[10,11]$. Likewise, a closer examination of the motives of the Farook - Malik matrimonial union could have pointed to obvious commonalities in their radical Islamic views and lifestyle. While the psychological evaluations for immigration could not necessarily predict the gruesome crimes this couple subsequently committed, it could have revealed warning signs for authorities to follow with greater rigor.

\section{Ethical and Validity Considerations}

In the case of the proposed psychological evaluations to all immigrant types across the board, several ethical issues should be considered. The first concern involves the consent for a psychological evaluation which is ethically required $[18,22]$ of all subjects in a forensic psychology study. Ordinarily, consent should be obtained from all participants at the outset of an evaluation, without undue pressure on subjects to provide it (which may not necessarily conform to the situation of an immigration application). When undue pressure on subjects is present, the results of the evaluation could be skewed in the direction of defensive response patterns, which may not accurately reflect upon the true motives of the individuals studied. While this could potentially present a threat to the validity of the findings because of defensiveness, and could potentially hamper terrorism preventive efforts, the requirement to participate in a psychological evaluation is likely to be perceived by most as no more than another tier in the already cumbersome immigration process. As it were, most immigration applicants are required to produce a variety of personally revealing documents and other personal details about themselves (e.g., financial, medical, etc.) and about their circumstances (e.g., birth certificates, school diplomas, employment pay-stubs, etc.) anyhow. Thus, adding a psychological evaluation to the already long list of intrusive procedures that immigrants are required to undergo will not be perceived as undue pressure, and therefore, would not violate basic rights for provision of a consent to be evaluated since they tacitly agreed to be evaluated.

The other ethical concern (and therefore also a potential threat to the validity of the evaluation results) is the concern that the evaluator is appointed by a federal agency, which could confer upon the examiner an inherent bias against the immigrant, as is the typical stance of federal authorities [14,10,11,21]. It is therefore easy to understand how psychological evaluations to all immigration applicants initiated by immigration authorities could be seen as inherently unethical, and the evaluator likened to a "hired-gun" for the government. While representing a challenge, this question also directs the forensic psychology expert's disposition in each case assessed. The obligation of the evaluator is to study the truth about the psychological aspects of the particular immigration case, regardless of the referral source. Furthermore, it is never the role of the psychology expert to offer opinions about any legal matters regarding the case, which are within the absolute and only purview of legal authorities [14,10,11,21].

\section{Conclusion}

The application of scientific methodology to the prevention of terrorism could enhance the safety of all Americans, while at the same time, streamline existing preventive protocols, and improve the vetting process of immigrants. Psychological assessments for immigration have been an invaluable tool in the aid of immigration authorities in the past two decades to assist in decision making regarding a variety of immigration applicants. The same psychological evaluations for immigration, if applied systematically across the board to all categories of immigration applicants, can also generate a terrorism risk assessment for each individual. Subsequently, immigration and homeland security authorities can then deploy appropriate terrorism preventive measures that are coherent and commensurate with the level of risk each immigrant more likely poses.

\section{References}

1. Aranda R (2016) Living in the shadows: Plight of the undocumented. J Clin Psychol 72(8): 795-806.

2. Conde YM (1999) Operation Pedro Pan: The Untold Exodus of 14,048 Cuban Children. Taylor \& Francis, New York, USA.

3. Pitti JA, Castaneda A, Cortes C (2004) Five views: An ethnic historic site survey for California. Mexican Americans in California.

4. Kean TH, Hamilton LH, Ben-Veniste R, Kerrey B, Fielding FF, et al. (2004) The 9/11 Commission Report. W.W. Norton, New York, USA.

5. Kephart J (2005) Immigration and terrorism. Center for Immigration Studies. 
6. Zakem V, Meszaros C, Scism D, McGee S (2012) Implications of international events on homeland security: A case study of the Arab Spring. Homeland ecurity Studies and Analysis Institute, pp. 11.

7. Comey JB (2015) Worldwide threats and homeland security challenges.

8. Vaisman-Tzachor R (2007) Profiling terrorists. Journal of Police Crisis Negotiations 7(1): 27-61.

9. Vaisman-Tzachor R (2003) Psychological assessment protocol in Federal Immigration Courts. The Forensic Examiner 12(3\&4): 34-41.

10. Vaisman-Tzachor R (2012) Psychological evaluations in Federal Immigration Courts: Fifteen years in the making - Lessons learned. The Forensic Examiner 21(2): 42-53.

11. Vaisman-Tzachor R (2012) The Book of Terrorism. Cambridge Brick House, Lawrence,USA.

12. Cervantes JM, Mejia OL, Mena A (2010) Serial migration and the assessment of extreme and unusual psychological hardship with undocumented Latina/o families. Hispanic Journal of Behavioral Sciences 32(2): 275-291.

13. Frumkin I, Friedland J (1995) Forensic evaluations in immigration cases: Evolving issues. Behavioral Sciences and the Law 13(4): 477 489

14. Vaisman-Tzachor R (2014) Psychological assessment protocol for asylum applications in Federal Immigration Courts. Annals of the American Psychotherapy Association.

15. American Bar Association (2010) The 2010 Federal Rules Book. American Bar Association Publishing, Chicago, USA.

16. Otto RK, Heilburn K (2002) The practice of forensic psychology: A look toward the future in light of the past. Am Psychol 57(1): 5-18.

17. Weiner IB, Hess AK (2006) The Handbook of Forensic Psychology ( $3^{\text {rd }}$ Edition). John Wiley \& Sons, Hoboken, USA.

18. American Psychological Association (1991) Specialty guidlines for forensic psychologists. Law and Human Behavior 15(6): 655-665.
19. American Psychological Association (1985) Standards for Educational and Psychological Testing. Author, Washington, USA.

20. Babitsky S, Mangraviti JJ, Babitsky A (2006) The A-Z Guide to Expert Witnessing. Seak, Inc, Flamouth, USA.

21. Vaisman-Tzachor R (2006) Psychological profiles of terrorists. The Forensic Examiner 15(2): 6-17.

22. American Psychological Association (2016) Ethical Principles and Code of Conduct.

23. Ribeiro JD, Bodell LP, Hames JL, Hagan CR, Joiner TE (2013) An empirically based approach to the assessment and management of suicide behavior. Journal of Psychotherapy Integration 23(3): 207-221.

24. Franklin JC, Ribeiro JD, Fox KR, Bentley KH, Kleiman EM, et al. (2017) Risk factors for suicidal thoughts and behaviors: A meta-analysis of 50 years of research. Psychol Bull 143(2): 187-232.

25. Post J, Denny L (2002) The terrorists in their own words. Paper presented at the International Society of Political Psychology Conference, Berlin, Germany.

26. Shermer M (2006) Murdercide: Science unravels the myth of suicide bombers. Scientific American 294(1): 34.

27. Silke A (2003) Terrorists, Victims and Society: Psychological Perspectives on Terrorism and Political Violence. Wiley, Hoboken, USA

28. Zagorin A, Duffy M (2005) Inside the interrogation of detainee 063 Time 165(25): 26-33.

29. Ragavan C (1999) A safe haven, but for whom?? U.S. News and World Report, November 15.

30. Matter of Ali (2005) 554 Federal Reporter - second series 1039.

31. Serrano RA, Esquivel P, Knoll C (2015) Everything we know so far about the San Bernardino terror attack investigation so far. Los Angeles Times.

Your next submission with Juniper Publishers will reach you the below assets

- Quality Editorial service

- Swift Peer Review

- Reprints availability

- E-prints Service

- Manuscript Podcast for convenient understanding

- Global attainment for your research

- Manuscript accessibility in different formats (Pdf, E-pub, Full Text, Audio)

- Unceasing customer service

Track the below URL for one-step submission https://juniperpublishers.com/online-submission.php 